\title{
Análise de impactos ambientais da prática da escalada na Serra do Lenheiro, São João del-Rei, MG
}

Analysis of environmental impacts of climbing practice in Serra do Lenhelro, São João del-Rel, MG

Webert Tadeu Resende ${ }^{1}$, André Batista de Negreliros²

1 - Bacharel em Geografia pela Universidade Federal de São João del-Rel, Brasll. htTpS://0rcidorog/0000-0001-8163-8097.

2 - Laboratório de Hidrologia e Análse Ambiental, Géócrafo, Professor Adjunto do Departamento de Geociênclas e do Programa de Pós-graduação em Geografia da UnverSIDAde FederRL de SÃo JoÃo del-Rel, Brasil. HTTPS://0RCID.0RG/0000-0002-5278-5546.

E-MAL:: WeBERTRESENDE@YAHO0.COM.BR, ANDREBNEGRERROS@UFS.EDU.BR

Abstract: Located in the county of São João del-Rei, MG, Serra do Lenheiro has provided opportunities for visitation and sports practices in the last decades. By having ideal characteristics of rock outcrops, it has always received climbers and mountaineers from all over Brazil. However, in the last years, there was a large increase in the number of climbing practitioners and a significant change in the modalities sought there (Boulder and Sports Climbing). With an expansion of those sports, as well as due to the opening of new areas for climbing in the region, some environmental impacts ensued. This study seeks to identify and analyze those environmental impacts, positive and negative, related to sports activities in the area. Given the considerable increase of climbers visiting natural sites for this purpose, it is necessary to pay attention to the conservation and preservation of the area explored for climbing, seeking to contribute towards minimum environmental impact.

Resumo: Situada no município de São João del-Rei, MG, a Serra do Lenheiro tem sido objeto de visitas e práticas esportivas nas últimas décadas. Por possuir características ideais de afloramentos rochosos, o lugar sempre recebeu escaladores e montanhistas de todo o Brasil, porém nos últimos anos houve grande aumento no número de praticantes de escalada e significativa mudança nas modalidades buscadas na Serra do Lenheiro (Boulder e Escalada Esportiva). Com a ampliação do esporte e também devido à abertura de novas áreas para a escalada na região, surgiram impactos ambientais no local. Este estudo procura identificar e analisar os impactos ambientais, positivos e negativos, relacionados ao tema. Diante do aumento considerável de escaladores que visitam locais naturais, é necessária grande atenção quanto aos cuidados relacionados à conservação e preservação da área utilizada, contribuindo com o mínimo impacto ao ambiente utiliado para a escalada.
Citation/Citação: Resende, W. T., Negreiros, A. B. (2020). Análise de impactos ambientais da prática da escalada na Serra do Lenheiro, São João del-Rei, MG. Terræ Didatica, 16, 1-8, e020011. doi: 10.20396/ td.v16i0.8654249.

Keywords: Environmental Impacts, Conservation, Serra do Lenheiro.

Palavras-chave: Impactos Ambientais, Conservação, Serra do Lenheiro.

\section{Manuscript/Manuscrito:}

Received/Recebido: 28/12/2018

Revised/Corrigido: 08/02/2020

Accepted/Aceito: 30/03/2020

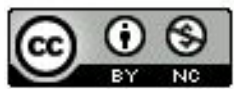

\section{Introdução}

As atividades outdoor (ao ar livre) têm sido procuradas cada vez mais por um número crescente de pessoas e praticantes de esportes desse tipo de modalidade. Muitas vezes a busca pelo contato direto com a natureza se dá por meio de passeios ou práticas esportivas como caminhadas ou travessias, mountain bike, escalada ou rapel, motocross, camping e outros esportes. Dentre essas modalidades, uma das mais praticadas e que atrai o interesse de muitos esportistas é a de escalada em rocha, na qual se insere no espectro de atividades do montanhismo. O estudo realizado por (Bodens, 2013), resgata a história do esporte, que tem suas origens nos diferentes interesses em se conquistar montanhas, seja científico, religioso, econômico, ou até militar. Dentre as motivações para a prática do esporte, podemos também considerar a realização pessoal em explorar lugares montanhosos antes não alcançados por seres humanos ou de difícil acesso.
Diante do aumento na quantidade e na frequência dos praticantes desse tipo de atividade esportiva, novas áreas estão sendo abertas e exploradas para finalidades esportivas ou de turismo de aventura. Com o fluxo crescente de pessoas em áreas relativamente novas para esse fim, algumas medidas e ações devem ser observadas diante do potencial de alguns impactos ambientais negativos que podem ser gerados a partir da grande circulação de pessoas por essas áreas. A implantação e existência do uso de trilhas representam uma interferência do homem no ambiente natural, provocando impacto físico, visual e sonoro. Ao mesmo tempo, restringem essa interferência a um único e delimitado itinerário (Hammitt et al., 2015).

Dessa forma, o presente estudo busca analisar e compreender como o uso e a prática de esportes, especificamente a Escalada em rocha, nas modalidades de Escalada Esportiva e Boulder, são desenvolvidos no espaço na Serra do Lenheiro em Minas Gerais, e os possíveis impactos ambientais gerados

\begin{tabular}{c|c|c|c|c|c}
\hline (C) Terrae Didat. & Campinas, SP & v.16 & $1-8$ & $\mathrm{e} 020009$ & 2020 \\
\hline
\end{tabular}



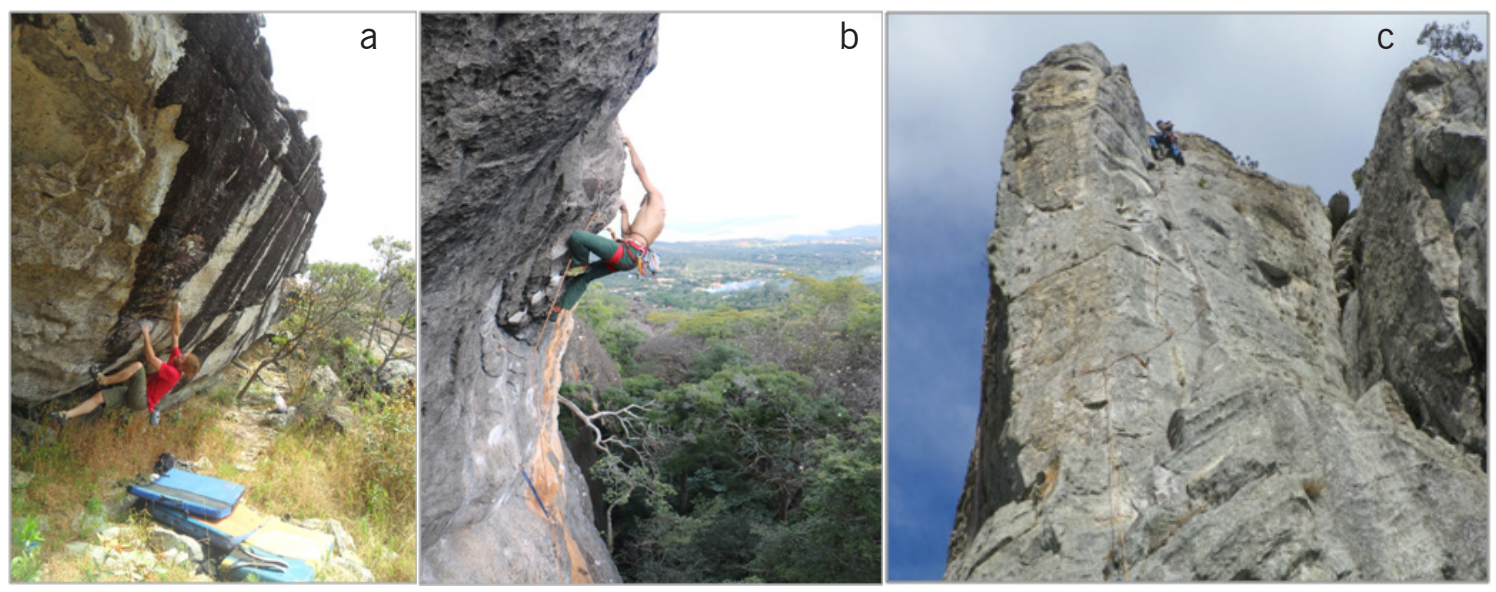

Figura 1. a: Escalador na modalidade Boulder com o uso de crash pad. (colchão). b: Escalada esportiva; com utilização de grampeação fixa, na qual as proteções fixadas não podem ser retiradas. c: Escalada em móvel; as proteções permanecem móveis em fendas ou fissuras na rocha, podendo ser retiradas após a escalada

por essa atividade. De acordo com (Vamerlati \& Cornacini 2011), impacto ambiental pode ser entendido como qualquer alteração no meio ambiente ou em algum de seus componentes por determinada ação ou atividade humana.

A escalada na serra do Lenheiro se originou no final da década de 1970, com a implantação do $11^{\circ}$ Batalhão de Infantaria de Montanha Tiradentes e o Centro de Instrução de Montanha (CEMONTA) na cidade de São João del-Rei. O espaço foi escolhido por conter faces íngremes e escarpadas que podem ser utilizadas para o treinamento de práticas verticais do Exército Brasileiro e devido à proximidade com o centro urbano da cidade. Após a instalação do Batalhão do Exército e com a evolução das técnicas e equipamentos de escalada, a serra do Lenheiro tornou-se um importante e conhecido setor de Escalada Tradicional (Móvel) ${ }^{1}$ no Brasil. A qualidade da rocha e grande quantidade de fendas e fissuras possibilitam a prática dessa modalidade e sem a necessidade de fixação de grampos, usando apenas as proteções naturais que a rocha oferece.

A Escalada Esportiva, com o tempo, começou a se desenvolver no país, pois com a fixação de grampos na rocha seria possível alcançar lugares ainda não explorados, de alta dificuldade e com a diminuição dos riscos de acidentes para o escalador, uma vez que as proteções eram fixas. Isso levou a uma grande evolução no esporte e uma busca por novos locais que pudessem ser abertas novas vias de escalada, cada vez mais difíceis e desafiadoras.

A necessidade de treinamentos e fortalecimento para vias de escalada mais exigentes levou à procura

$1 \quad$ Escalada tradicional (móvel): Realizada com o uso de proteções móveis (peças que se encaixam em fendas), ou seja, sem a utilização de grampeação fixa. por linhas de escalada em blocos menores ou matacões. Estes apresentavam inicialmente mínimo risco de acidentes e poderiam ser feitos sem equipamentos de segurança, porém de extrema dificuldade, pois simulariam o esforço exigido nas rotas de escalada, surgindo então a modalidade Boulder. Essa modalidade que cresce em todo o país vem ganhando cada vez mais praticantes. A Serra do Lenheiro contém diversos blocos de quartzito, de todas as formas, tamanhos e inclinações que propiciam a prática de Boulder².

\section{Revisão Bibliográfica}

Escalar uma montanha sempre se mostrou uma atividade muito arriscada e perigosa, pois os escaladores podem enfrentar diversos tipos de riscos na trajetória da base até o cume da montanha. Como, por exemplo, mudanças bruscas no clima, quedas de blocos de rocha, falha em algum equipamento de escalada e etc. Para diminuir os riscos de acidentes, foram criadas as proteções fixas, que uma vez colocadas na rocha, permanecem por tempo indeterminado. As proteções geralmente utilizadas fixas são os grampos e chapeletas e com distância entre elas é pequena, mantendo certo nível de conforto para que o praticante possa se concentrar apenas na resolução da escalada (Bodens, 2013).

Com o desenvolvimento da escalada no Brasil nos últimos anos, surgiu à necessidade de ampliar os locais de escalada. Locais que oferecem as condições ideais para essa atividade, até então pouco

2 Boulder: escalada realizada em matacões, blocos de rocha, geralmente menores do que os escalados na modalidade esportiva. Não se usa corda. 0 escalador utiliza apenas a sapatilha, o carbonato de magnésio e na maioria das vezes o colchão para amortecer as quedas, o "crash pad".

\begin{tabular}{c|c|c|c|c|c}
\hline C Terrae Didat. & Campinas, SP & v.16 & $1-8$ & e20009 & 2020 \\
\hline
\end{tabular}


visitados, começaram a receber visitantes para esse fim. E nesse processo foram gerados impactos ambientais, tal como, abertura trilhas de acesso aos setores, fixação de proteções nas rochas, aumento no número de frequentadores dos locais, descarte de lixo e etc.

\section{Impactos ambientais da escalada em rocha}

Sobre o conceito de impacto ambiental, há diversas definições. Segundo a Resolução do Conselho Nacional do Meio Ambiente, CONAMA n ${ }^{\circ}$ 001 de 1986, a definição de impacto ambiental é:

Qualquer alteração das propriedades físicas, químicas ou biológicas do meio ambiente, causada por qualquer forma de matéria ou energia resultante das atividades humanas, que direta ou indiretamente afetem: I - a saúde, a segurança e o bem-estar da população; II - as atividades sociais e econômicas; III - as condições estéticas e sanitárias do meio ambiente; IV - a qualidade dos recursos ambientais.

Para (Meneguzzo \& Chaicouski 2010) o termo impacto ambiental apesar de ser amplamente empregado para referir-se a aspectos negativos decorrentes de ação antrópica, pode possuir conotação positiva. Isto ocorre devido ao fato de que um impacto pode ocorrer na forma negativa ou positiva, isto é, trazer malefícios ou benefícios ao ambiente.

Já o conceito de degradação ambiental, apesar de abrangente, apresenta um caráter negativo. É definido pela legislação através da lei no 6.938 de 31 de agosto de 1981 da Política Nacional de Meio Ambiente, artigo $3^{\circ}$, inciso II da seguinte como a "degradação da qualidade ambiental, a alteração adversa das características do meio ambiente." E pelo decreto federal 97.632/89 como um:

\section{"Conjunto de processos resultantes de danos no meio ambiente, pelos quais se perdem ou se reduzem algumas de suas propriedades, tais como, a qualidade ou capacidade produtiva dos recursos ambientais".}

Denomina-se degradação ambiental como uma destruição gradativa de um ambiente em equilíbrio. Impactos ambientais que levam a degradação ambiental podem ser exemplificados como: as queimadas, que destroem a flora e afugentam a fauna; a dejeção de resíduos não tratados em rios, que acabam fundamentalmente com a fauna aquática e a potabilidade da água; a desertificação, que provoca perda de produtividade do solo devido a manejo inadequado das culturas, uso excessivo de fertilizantes e destruição da cobertura vegetal (Vamerlati \& Cornacini, 2011).

Dentre os efeitos relacionados à degradação ambiental da Serra do Lenheiro está à poluição de cursos d'água e córregos e o descarte de lixo nas estradas e trilhas e que cortam a Serra. Dá-se o nome de poluição a qualquer degradação (deterioração, estrago) das condições ambientais, do habitat de uma coletividade humana (Vamerlati \& Cornacini, 2011). É uma perda, mesmo que relativa, da qualidade de vida em decorrência de mudanças ambientais. São chamados de poluentes os agentes que provocam a poluição, como um ruído excessivo, um gás nocivo na atmosfera, detritos que sujam os rios ou praias ou ainda um cartaz publicitário que degrada o aspecto visual de uma paisagem. A figura 2 mostra algumas das trilhas de acesso ao setor de escalada Ave Maria.
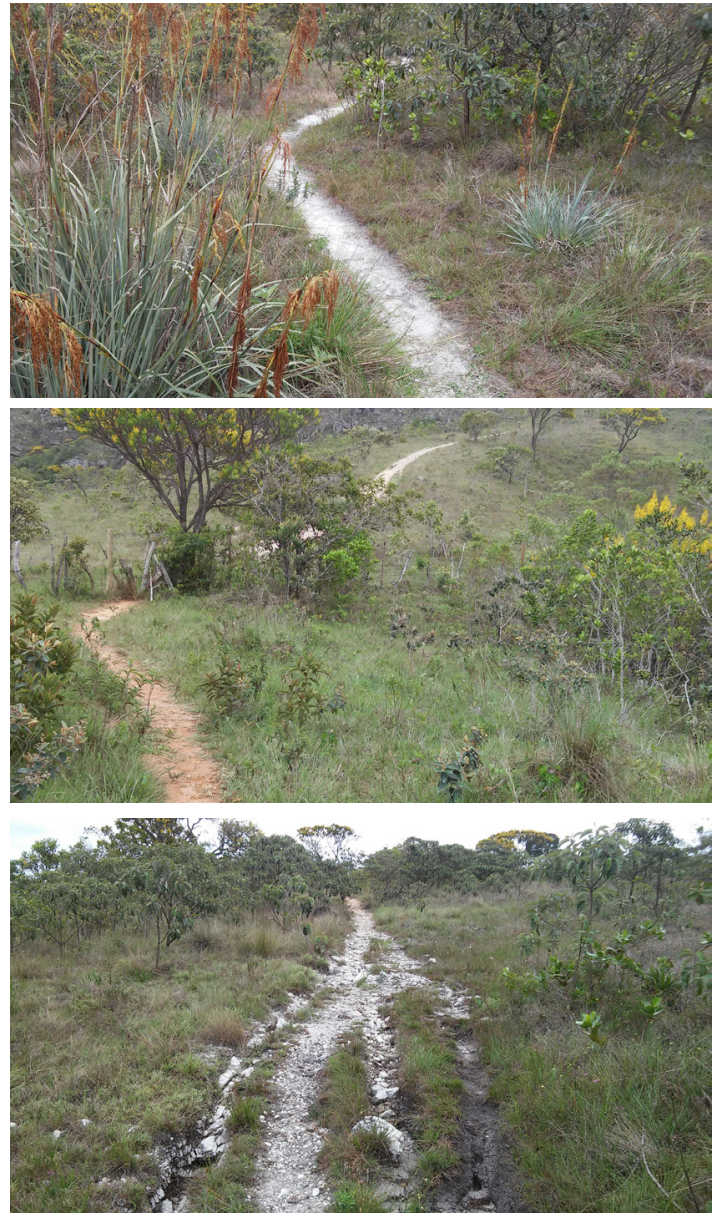

Figura 2. Trilhas de acesso ao setor de escalada "Ave Maria". Nesta figura a trilha encontra-se com abertura de sulcos devido ao trafego de motos e bicicletas

\begin{tabular}{|c|c|c|c|c|c|}
\hline (C) Terrae Didat. & Campinas, SP & v.16 & $1-8$ & $\mathrm{e} 020009$ & 2020 \\
\hline
\end{tabular} 
Os impactos relacionados à atividade de escalada na Serra do Lenheiro estão, sobretudo, na abertura de novas trilhas de acesso aos setores, descarte de lixo na base de vias de escalada e fixação de proteções na rocha. Segundo (Baker, 1999) o Serviço Florestal dos EUA (USFS) passou por uma política que restringiria a escalada nas áreas selvagens. Uma regra proposta foi a de proibir "âncoras fixas", um tipo de parafuso usado por alpinistas, com a intenção de diminuir os impactos mais sérios de escalar em hábitats de penhascos únicos, de acordo com pesquisadores.

Para salvar o esporte de uma estagnação total, impunha-se que a comunidade local de escaladores resolvesse, voluntariamente, limitar os meios empregados em conquistas e ascensões subsequentes. Tal atitude era inclusive urgente, a cidade do Rio de Janeiro e seus arredores, por exemplo, já haviam sido severamente impactados com a fixação de inúmeros grampos desnecessários. Estes grampos desfiguram por completo o caráter natural das paredes rochosas e constituem-se, em termos ecológicos, uma forma de poluição estética tão indesejável quanto o lixo espalhado ao longo de trilhas, acampamentos e na base de certas escaladas. (Ilha 1983).

De acordo com a ética na conquista de vias de escalada, a colocação de proteções fixas somente deve ser feita em rochas que não ofereçam possibilidade de proteção natural como fendas e fissuras. As escarpas da Serra do Lenheiro possuem muitas dessas características, o que viabiliza a Escalada Móvel, assim utilizando o mínimo de grampos para a prática. Na escalada de Boulder, não é permi- tida a fixação de proteções, por se tratar de blocos normalmente baixos, nos quais a segurança é feito por meio de colchões (crash pads). Dessa forma, são poucas as vias totalmente protegidas por grampos na Serra do Lenheiro em comparação a outros locais no Estado de Minas Gerais, como Serra do Cipó, Arcos, Lapa do Antão e Baú de Minas. A figura 3 mostra algumas das regras locais disponibilizadas no Guia de Boulder's e nas mídias sociais para a visita ao setor Ave Maria na Serra do Lenheiro.

\section{Caracterização da Área de Estudo}

A Serra do Lenheiro está localizada na cidade de São João del-Rei, Estado de Minas Gerais, Brasil. $\mathrm{Na}$ serra, também se insere um parque ecológico municipal, segundo o Decreto Municipal n ${ }^{\circ} .2 .160$ de 28 de setembro de 1993 e pela Lei ${ }^{\circ}$. 3.356 de 01 de abril de 1998 que se situa no contato entre a Serra e os bairros adjacentes. A figura 4 localiza o Município de São João del-Rei em relação ao território brasileiro

A estrutura litológica da Serra do Lenheiro se caracteriza como um anticlinal falhado, caracterizado por várias falhas de empurrão que vertem para o norte. Apresentando diferentes litotipos, tais como, metarenitos, metassiltitos e metaconglomerados com diferentes espessuras (Ferreira et al., 2017). Já o clima da região é do tipo Cwb segundo a classificação de Köppen-Geiger, apresentando verões chuvosos e invernos secos, com temperaturas médias mensais variando entre $22^{\circ}$ C e $15^{\circ}$ C. (Barbosa et al., 2015).

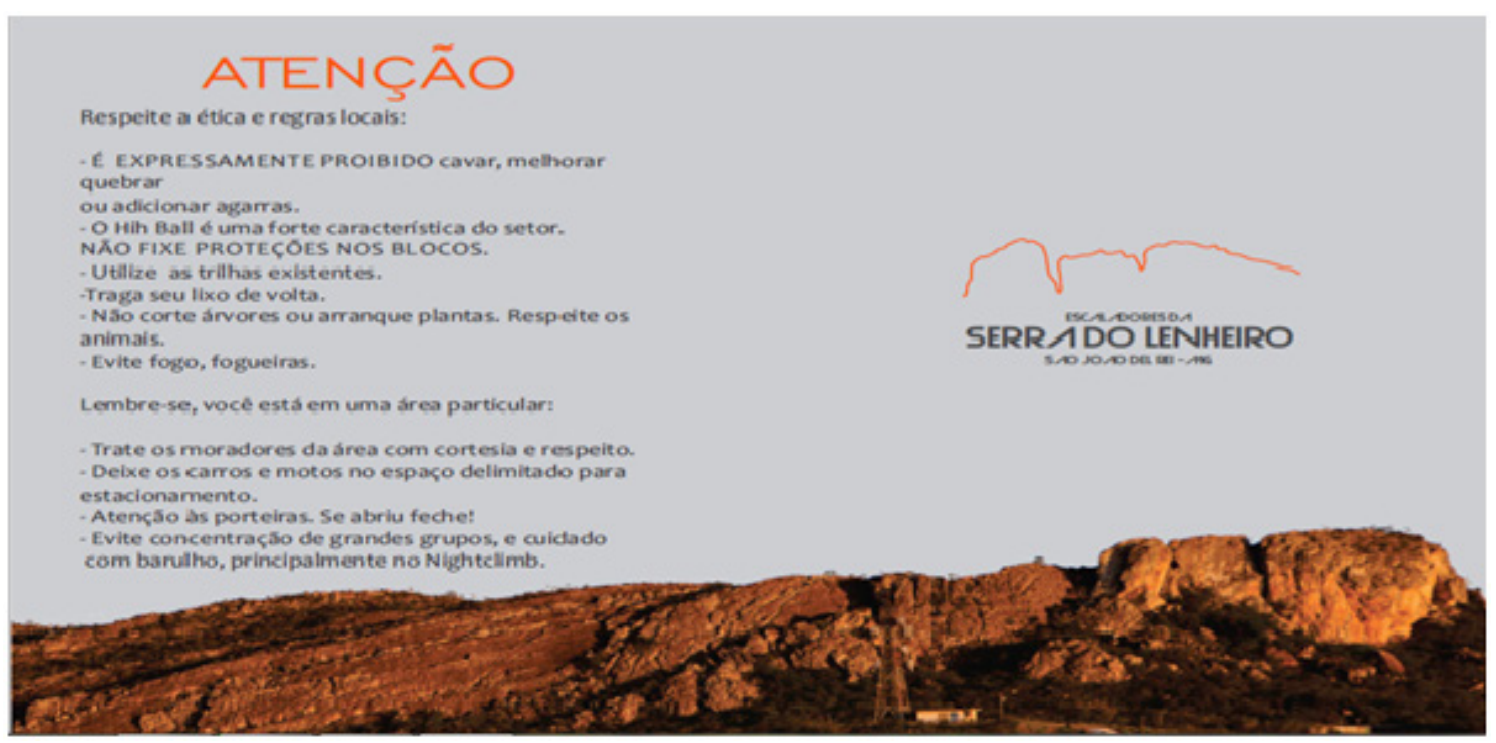

Figura 3. Regras para utilização do Setor Ave Maria. Fonte: Guia de Boulder's Ave Maria, Serra do Lenheiro (2015)

\begin{tabular}{c|c|c|c|c|c}
\hline (C) Terrae Didat. & Campinas, SP & v.16 & $1-8$ & $\mathrm{e} 020009$ & 2020 \\
\hline
\end{tabular}


A serra do Lenheiro é caracterizada principalmente pela vegetação de cerrado e campos rupestres, que se estende por grande parte da região dos campos das vertentes. Segundo levantamento bibliográfico realizado por (Vasconcelos, 2011) em geral, os campos rupestres ocorrem principalmente acima de $900 \mathrm{~m}$ de altitude, em montanhas cujas rochas são de origem pré-cambriana que foram remodeladas por movimentos tectônicos a partir do Paleógeno, estando associados, principalmente, a afloramentos de quartzito, arenito e minério de ferro. Esses campos encontram-se distribuídos principalmente ao longo da Cadeia do Espinhaço, embora áreas isoladas desse tipo de vegetação também sejam encontradas nas serras do Brasil Central: Chapada dos Veadeiros e Serra dos Pirineus, ambas em Goiás; e Serra da Canastra, Serra do Lenheiro; Serra de São José e Itutinga no Estado de Minas Gerais.

O setor "Ave Maria" recebeu este nome segundo história local de escaladores de São João del-Rei devido à conquista da primeira via de escalada do setor (Via Ave Maria) onde o escalador local, Luiz Cláudio sofreu uma grande queda da própria via e no susto do momento gritou "Ave Maria" então a rota ficou batizada com esse nome. Como esta ficou sendo a única via do setor por muito tempo, o setor também recebeu o nome de Ave Maria. As outras vias abertas posteriormente ao ocorrido seguiram a linha "religiosa" na concepção dos nomes.

Com o crescimento do esporte e o aumento no número de frequentadores nos últimos anos na Serra do Lenheiro que buscam o setor da "Ave Maria" para a prática de escalada de Boulder's, percebeu-se a necessidade de criar um material de orientação para os mesmos. Foi então realizado um trabalho de catalogação e registro das linhas de escalada nos blocos do setor e também o estabelecimento de algumas condutas práticas de conservação e preservação do local. Com as informações obtidas durante todo o período do estudo (um ano) foi produzido o primeiro Croqui de Boulder's da Ave Maria, Serra do Lenheiro que posteriormente foi disponibilizado em formato digital em grupos e sites relacionados ao tema de escalada. A produção do croqui contou com a ajuda de escaladores locais e de outras regiões, no sentido de estabelecer regras para o uso e visitação dos locais de escalada. A figura 5 mostra a capa e a contracapa com os autores do Croqui de Boulder's do Setor de escalada Ave Maria em São João del-Rei.

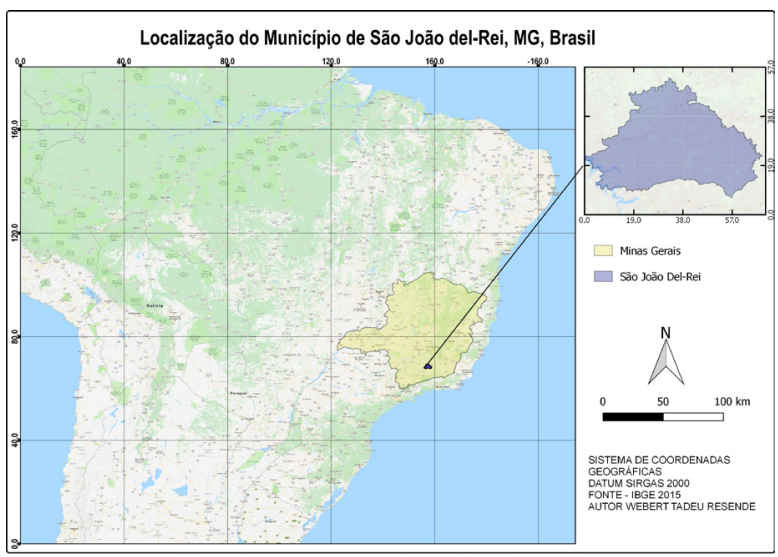

Figura 4. Mapa de Localização de São João del-Rei, MG
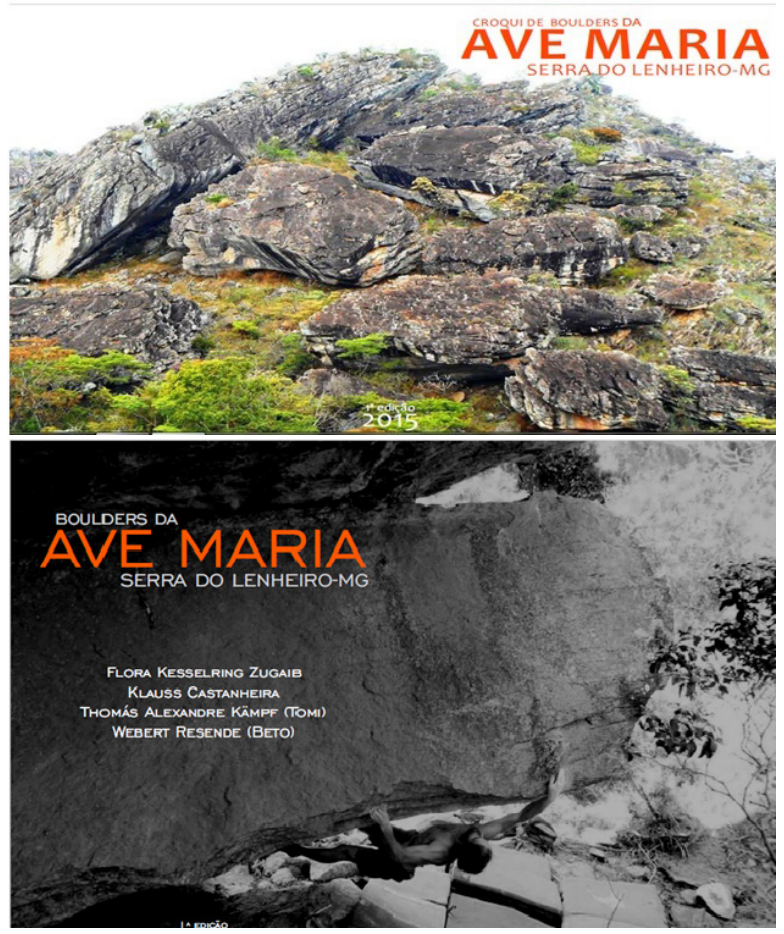

Figura 5. Capa (A) do Croqui de Boulder's da Ave Maria, Serra do Lenheiro, MG, Ed. 2015. (B) $1^{\text {a }}$ edição do Croqui de Boulder's, autores do guia

\section{Metodologia}

Em primeiro momento, buscou-se contemplar uma análise histórica da Escalada. Em segundo momento, realizou-se pesquisa de campo com o objetivo de conhecer e localizar os principais setores de escalada na Serra do lenheiro, por meio de marcações de pontos por aparelhos de GPS, fotografias das faces de escalada e entrevistas com escaladores locais e visitantes. Em seguida, tendo em mãos a localização dos setores, foi feita sistematização dos dados para mapeamento. Espera-se que a investigação possa contribuir para um

\begin{tabular}{c|c|c|c|c|c|}
\hline (C) Terrae Didat. & Campinas, SP & v.16 & $1-8$ & $\mathrm{e} 020009$ & 2020 \\
\hline
\end{tabular}


maior conhecimento das atividades de escalada na região do estudo.

Também foi realizada uma pesquisa com os praticantes de escalada e visitantes da Serra do Lenheiro de forma geral, envolvendo grupos de redes sociais de praticantes da atividade esportiva, questionários foram disponibilizados por ferramenta online do site Google Drive. Os participantes responderam às questões propostas, com a participação de 36 pessoas de diversas cidades do estado e do Brasil. O questionário foi composto por cinco perguntas que procuraram analisar: o tempo frequentado por cada escalador na serra do Lenheiro; os setores mais

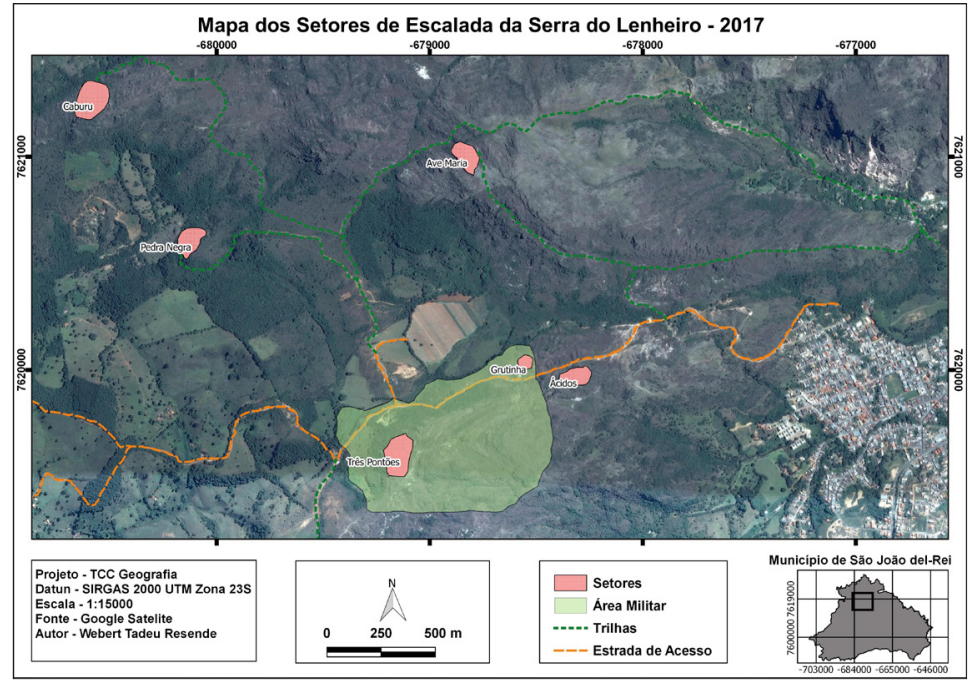

Figura 6. Mapa dos setores de escalada da Serra do Lenheiro visitados; as modalidades mais praticadas na serra; a frequência das visitas aos setores; e o número de pessoas por visita à serra.

\section{Resultados e Discussão}

Os setores onde é realizada a práticas de escalada na Serra do Lenheiro estão distribuídos em diversos locais, que podem ser acessados por estradas ou trilhas. A figura 6 mostra o mapa de localização dos setores de escalada distribuídos na Serra do Lenheiro.

Com o aumento no número de praticantes de escalada nos últimos anos em todo o país, novas áreas ainda não visitadas para esse fim começaram a serem exploradas. Além do crescente número de escaladores, também foi observado aumento na frequência destes a locais visitados; consequentemente aumentam os impactos ambientais. As figuras 7 e 8 exemplificam entrevista realizada com escaladores a locais próximos a São João del-Rei. O acréscimo no número de escaladores em São João del-Rei e municípios vizinhos reflete tendência nacional, pois o esporte é cada vez mais popular. a. A figura 7A mostra que a maior parcela de frequentadores e escaladores que visitam a Serra do Lenheiro já a conhecem no período entre 1 a 3 anos, seguido dos frequentadores entre 4 a 10 anos. A figura 7B mostra que a frequência de escaladores é maior que 1 a 3 vezes por ano, porém são bem distribuídos na frequência de visitas, entre as classes 1 a 3 vezes por semana e 1 a 3 vezes por mês. A figura 7C demonstra que grupos de 3 e 4 pessoas são o tipo mais comum de visitas aos setores de escalada, seguidos por grupos de 2 e 5 . A figura 7D indica que a modalidade de escalada mais procurada na Serra do Lenheiro é a Escalada Esportiva , seguida pelo Boulder e por fim a Escalada Móvel. A partir de evidências, percebe-se uma mudança no perfil dos escaladores visitantes da serra, que tempo atrás buscavam mais a escalada móvel. A figura 8 revela que os setores mais procurados para escalada são respectivamente, Ave Maria, Ácidos e Pedra Negra.

De acordo com os dados obtidos na pesquisa, nota-se que existe número significativo de escaladores que procuram a serra para escalada, bem como aumento nas modalidades de Escalada Esportiva e Boulder. Assim, o aumento no número de visitantes aos locais de escalada pode modificar a dinâmica natural do ambiente e gerar impactos ambientais. Nos últimos anos, o número de praticantes de escalada aumentou em todo o mundo, fator explicado pelo desenvolvimento das técnicas, dos equipamentos de segurança e pelo maior interesse das pessoas por práticas esportivas. Com o aumento, os ambientes naturais onde se pratica a atividade sofrem maior pressão, resultando em aumento de impactos e podendo levar à degradação ambiental (Hammitt et al., 2015). Estudos sobre o tema são desenvolvidos em universidades como a Colorado State University, nos Estados Unidos e University of Basel, na Suíça. (Contaldo de Lara \& Barbosa Caldeira 2016). Algumas práticas foram adotadas na Serra do lenheiro com a intenção de conscientizar para preservação do local, como a instalação de placas educativas (Fig. 9).

\begin{tabular}{c|c|c|c|c|c|c}
\hline (C) Terrae Didat. & Campinas, SP & v.16 & $1-8$ & $\mathrm{e} 020009$ & 2020 \\
\hline \multicolumn{6}{|c|}{6}
\end{tabular}




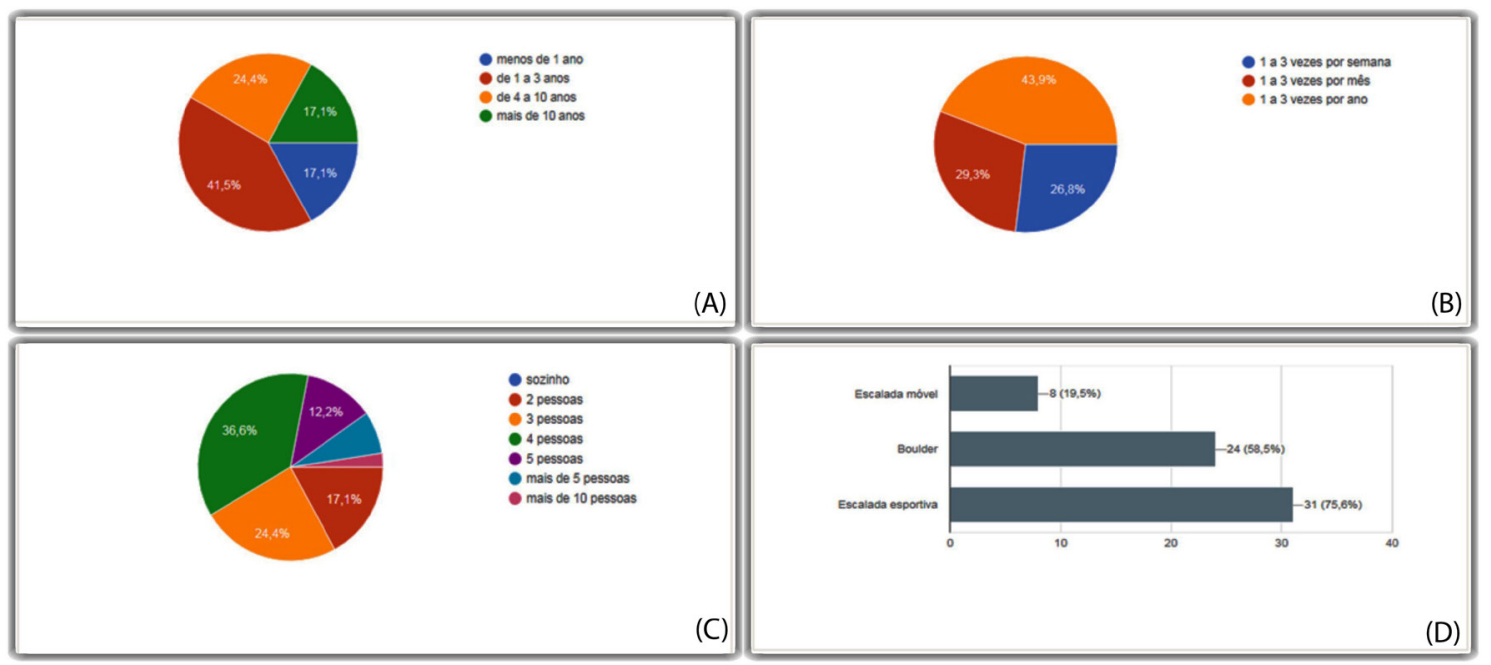

Figura 7. Respostas às perguntas: $(A)$ Há quanto tempo você frequenta a Serra do Lenheiro para a prática de escalada? (B) Com que frequência você visita a Serra? (C) Número de pessoas em seu grupo por visitas? (D) Qual(is) modalidade(s) você pratica com mais frequência na região?

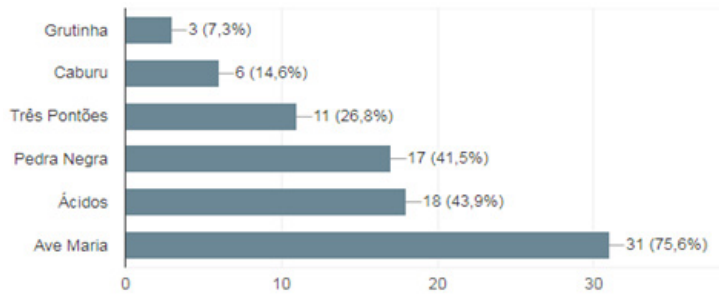

Figura 8. Respostas à pergunta: De maneira geral, qual setor você escalou mais na última temporada (2017)?

\section{Considerações Finais}

A cidade de São João del-Rei possui longo histórico de prática esportiva da escalada, por possuir afloramentos rochosos que possibilitam esse tipo de atividade e pela longa tradição do Batalhão do Exército na cidade. O esporte passa por crescimento acentuado no Brasil nos últimos anos, e cada vez mais são buscadas novas áreas para essa finalidade. Recentemente, na Serra do Lenheiro foi descoberto também um grande potencial para a prática da modalidade de Boulder, nos anos de 2013 e 2014, o que culminou na divulgação e posteriormente no aumento do número de frequentadores para a prática dessa modalidade de escalada. A cidade tonou-se importante setor no país, recebendo escaladores de lugares como Paraná, São Paulo, Rio de Janeiro, Belo Horizonte e de muitas cidades vizinhas.

O inventário realizado com a comunidade escaladora revela aumento no número de praticantes de escaladas e na frequência de visitas na área estudada. O aumento impacta diretamente o ambiente, pois o espaço tende a ser alterado com abertura de novas
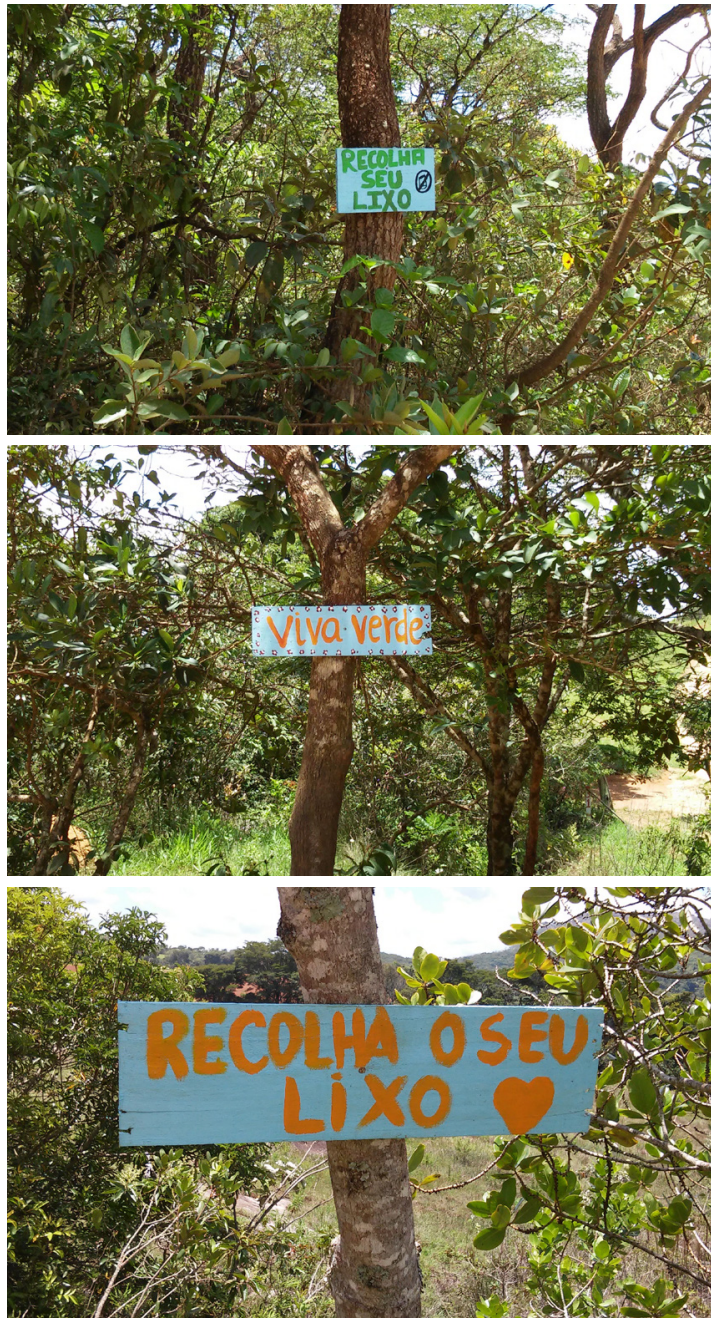

Figura 9. Placas colocadas em árvores (A, B, C), como exemplos de iniciativa de conscientização para preservação da Serra do Lenheiro

\begin{tabular}{c|c|c|c|c|c|}
\hline C Terrae Didat. & Campinas, SP & v.16 & $1-8$ & e020009 & 2020 \\
\hline \multicolumn{2}{|c|}{7} & & &
\end{tabular}


trilhas e clareiras para escalada dos blocos. Diante do aumento considerável de escaladores que visitam locais naturais, é necessário atentar para os cuidados relacionados à conservação e preservação da área utilizada, de modo a reduzir o impacto ambiental. Os escaladores tendem a contribuir para a preservação e manutenção do local, recolhendo lixo encontrado, demarcando apenas as trilhas de acesso aos setores e buscando utilizar poucas proteções fixas ancoradas às rochas. De acordo com Baker (1999) a educação deve funcionar, pois os alpinistas geralmente são conscientes da conservação e apoiarão as políticas baseadas na ciência. A autora acredita ser "arbitrário e prejudicial" proibir a inserção das peças utilizadas como âncoras fixas pelos praticantes. É necessário conscientizar e esclarecer todos os frequentadores de setores de escalada, visando minimizar os impactos gerados e ainda contribuir para a conservação e preservação dos locais frequentados.

\section{Referências}

Baker, B. (1999). Controversy over use of rock-climbing anchors may be missing the mark. BioScience, 49(7), 529. doi: 10.1093/bioscience/49.7.529.

Barbosa, H. S. L., Teixeira, P. H. S., Campos, A. C., Figueiredo, M. A., Rocha, L. C., \& Negreiros, A. B. (2015). Aspectos da degradação ambiental de uma trilha recreacional na Serra do Lenheiro, São João del-Rei, MG. Revista Territorium Terram, 3(5), 32-40.

Bodens, J. P. (2013). Diretrizes para avaliação do impacto ambiental da prática de boulder em Parques Nacionais e Estaduais: $O$ caso do Parque Estadual dos Pirineus (GO). TCC apresentado ao Departamento de
Geografia, Universidade de Brasília. 77p.

Castanheira, K., Resende, W., T., Kämpf, T. A., \& Zugaib, F. K. (2017). Boulder's da Ave Maria, Serra do Lenheiro, MG. Revista online Blog de Escalada.

Contaldo de Lara, D., Barbosa Caldeira, A. (2016). A Geografia da Escalada em Minas Gerais. Belo Horizonte, Brasil, Pontifícia Universidade Católica de Minas Gerais. Caderno de Geografia, 26(1), 2034. doi: 10.5752/p.2318-2962.2016v26nesp1p20.

Ferreira, A. C, Souza, E. M, Rocha, L. C, \& Figueiredo, M. (2017). A Geodiversidade Presente no Campo Escola de Montanhismo (Cemonta), Serra do Lenheiro, São João del-Rei. Anais do I Colóquio Mineiro de Geoconservação e I Simpósio Mineiro de Geopatrimônio, Ituiutaba, MG. p. 94-100.

Hammitt, W. E., Cole, D. N., Monz, C. A. (2015) Wildland Recreation: Ecology And Management. 3 ed., Wiley-Blackwell, $334 \mathrm{p}$.

Ilha, A. (1983). Manifesto da Escalada Natural. Rio de Janeiro, Mimeo, $8 \mathrm{p}$.

Meneguzzo, I. S., \& Chaicouski, A. (2010). Reflexões Acerca dos Conceitos de Degradação Ambiental, Impacto Ambiental e Conservação da Natureza. Londrina, Revista online Geografia, 19 (1), 181185. doi: 10.5433/2447-1747.2010v19n1p181

Vamerlati, J. S., \& Cornacini, R. F. (2011). Planejamento Ambiental. Curitiba-PR. Instituto Federal de Educação e Ciência do Paraná. 131p. (Educação a Distância).

Vasconcelos, M. F. (2011). O que são campos rupestres e campos de altitude nos topos de montanha do Leste do Brasil? Revista Brasileira de Botânica, 34(2), 241-246. doi: 10.1590/S0100-84042011000200012

WWF-Brasil (2006). Manejo de Escalada: Manual sobre questões atuais e a produção de um plano de manejo. $1^{\mathrm{a}}$ ed. WWF-Brasil. 72p. 